\title{
Endoscopic extradural supraorbital approach to the temporal pole and adjacent area: technical note
}

\author{
Fuminari Komatsu, MD, PhD, ${ }^{1}$ Masaaki Imai, MD, PhD, ${ }^{1}$ Hideaki Shigematsu, MD, ${ }^{1}$ Rie Aoki, MD, ${ }^{1}$ \\ Shinri Oda, MD, PhD, ${ }^{1}$ Masami Shimoda, MD, PhD, ${ }^{1}$ and Mitsunori Matsumae, MD, DMSc ${ }^{2}$ \\ 'Department of Neurosurgery, Tokai University Hachioji Hospital, Tokyo; and ²Department of Neurosurgery, Tokai University \\ School of Medicine, Kanagawa, Japan
}

\begin{abstract}
The authors' initial experience with the endoscopic extradural supraorbital approach to the temporal pole and adjacent area is reported. Fully endoscopic surgery using the extradural space via a supraorbital keyhole was performed for tumors in or around the temporal pole, including temporal pole cavernous angioma, sphenoid ridge meningioma, and cavernous sinus pituitary adenoma, mainly using 4-mm, $0^{\circ}$ and $30^{\circ}$ endoscopes and single-shaft instruments. After making a supraorbital keyhole, a $4-\mathrm{mm}, 30^{\circ}$ endoscope was advanced into the extradural space of the anterior cranial fossa during lifting of the dura mater. Following identification of the sphenoid ridge, orbital roof, and anterior clinoid process, the bone lateral to the orbital roof was drilled off until the dura mater of the anterior aspect of the temporal lobe was exposed. The dura mater of the temporal lobe was incised and opened, exposing the temporal pole under a 4-mm, $0^{\circ}$ endoscope. Tumors in or around the temporal pole were safely removed under a superb view through the extradural corridor. The endoscopic extradural supraorbital approach was technically feasible and safe. The anterior trajectory to the temporal pole using the extradural space under endoscopy provided excellent visibility, allowing minimally invasive surgery. Further surgical experience and development of specialized instruments would promote this approach as an alternative surgical option.
\end{abstract}

https://thejns.org/doi/abs/10.3171/2017.3.JNS162228

KEY WORDS anatomy; anterior clinoidectomy; endoscopic keyhole surgery; skull base; surgical technique

$\mathrm{A}$ DVANCEMENTS in microscopic techniques and meticulous anatomical analysis have developed modern microscopic skull base surgery. ${ }^{6,7,9,10}$ Moreover, the evolution of endoscopic endonasal skull base surgery in the last decade has allowed a minimally invasive direct approach to the anterior midline skull base with superb illumination. ${ }^{2,3,8}$ However, the corridor of endoscopic endonasal surgery is limited within the anterior midline, and therefore comprehensive management of skull base lesions through the endonasal route is impractical.

In contrast, endoscopic keyhole surgery provides transcranial routes to approach skull base lesions with minimal invasiveness, and the advantages of endoscopic surgery as well as excellent surgical results have been described in several reports. ${ }^{1,5,13,21}$ The authors have investigated endoscopic extradural skull base anatomy through the various keyholes as variations of endoscopic keyhole surgery, and have reported the potential advantages of endoscopic extradural keyhole approaches to the anterior, middle, and posterior cranial fossae. ${ }^{15-19}$ Of these approaches, the endoscopic extradural supraorbital approach has been developed as an alternative minimally invasive option to the conventional extradural frontotemporal approach. ${ }^{15,18,19}$ The results of anatomical studies demonstrated excellent exposure and visualization of skull base structures such as the sphenoid ridge, superior orbital fissure, optic canal, optic nerve, cavernous sinus, and even the middle cranial fossa via the supraorbital keyhole approach, $, 15,18,19$ but there 
have been no clinical reports of this approach. Thus, the authors present an initial technical report of endoscopic extradural keyhole surgery related to the temporal pole.

\section{Methods}

\section{Nuances of the Approach}

A supraorbital keyhole craniotomy is placed after eyebrow skin incision, and a $4-\mathrm{mm}, 30^{\circ}$ endoscope is introduced directly into the extradural space of the anterior cranial fossa through the supraorbital keyhole by peeling off the dura mater of the anterior skull base. The endoscope advances posteriorly in the extradural space until the sphenoid ridge appears, and the circumferential anterior cranial fossa structures are identifiable under the $30^{\circ}$ endoscopic view. The orbital roof and the base of the anterior clinoid process are visible medial to the sphenoid ridge. The lateral part of the anterior cranial fossa, composed of the frontal bone and the lesser and greater wings of the sphenoid bone, is drilled off until the anterior aspect of the temporal lobe dura is exposed, while the orbital roof is kept intact. Hence, the superior and lateral margins of the superior orbital fissure are also opened. Thus, a sufficient extradural corridor to the anterior aspect of the temporal lobe dura is prepared (Fig. 1). Opening of the anterior aspect of the temporal lobe dura allows one to reach the temporal pole from the anterior trajectory through the extradural corridor. As an expanded variation, performing an anterior clinoidectomy before dural opening provides a surgical corridor to the superior and lateral walls of the cavernous sinus (Fig. 1 upper).

\section{Endoscopy}

The operation is performed using $0^{\circ}$ and $30^{\circ}$ endoscopes. An irrigation system is used to maintain clear visibility. Use of the freehand technique-holding the endoscope in one hand and the surgical instrument in the other hand-is preferred to establish the extradural corridor. Once the surgical corridor is prepared, a bimanual technique similar to standard microsurgical manipulation is performed with fixation of the endoscope using a pneumatic holder system (UniArm, Mitaka). Single-shaft instruments are mainly used.

\section{Clinical Presentation}

The lessons learned from anatomical studies for clinical application are discussed. Three brain tumor cases related to the temporal pole were treated at Tokai University Hachioji Hospital. The endoscopic extradural supraorbital approach was used in all cases. The institutional ethics committee approved this study. All procedures performed in this study involving human participants were conducted in accordance with the latest version of the Declaration of Helsinki. Informed consent was obtained from all individual participants included in the study.

\section{Results}

\section{Illustrative Cases}

Case 1: Temporal Pole Cavernous Angioma

A 42-year-old man presented with epilepsy. MR images



FIG. 1. Schema of the endoscopic extradural supraorbital approach to the temporal pole. Upper: The blue area on the skull base indicates bone removal of the frontal and sphenoid bones to approach the temporal pole. The red area suggests the estimated bone removal area for the anterior clinoidectomy to expose the superior and lateral walls of the cavernous sinus. The endoscope is directed to the temporal pole through the supraorbital keyhole. Lower: Extradural space of the anterior and middle cranial fossa is seen through pinkish transparent bone to better understand the concept of this approach. The endoscope illuminates the anterior aspect of the temporal lobe dura through the extradural corridor via the supraorbital keyhole.

showed a 2-cm cavernous angioma in the temporal pole on the right (Fig. 2A and B). Medical treatment to control the epilepsy was insufficient, and endoscopic extradural supraorbital surgery was performed (Video 1).

VIDEO 1. Clip showing the pertinent details involved in Case 1. An endoscope is introduced into the extradural space via a supraorbital keyhole. The sphenoid ridge (SR) is drilled off. The anterior aspect of the temporal dura is exposed. The dura mater is incised and opened, exposing the temporal pole (TP) in the intradural space. A small corticotomy is made, and the tumor is visualized under an excellent endoscopic view. The border of the tumor is well visualized with superb illumination, allowing total removal. The dura mater is closed with stitches, and the supraorbital keyhole is closed. $\mathrm{CA}=$ cavernous angioma; $\mathrm{TD}=$ dura mater of the temporal lobe. Copyright Fuminari Komatsu. Published with permission. Click here to view.

After a supraorbital keyhole was made, a 4-mm, $30^{\circ}$ endoscope was introduced into the extradural space. The endoscope proceeded posteriorly in the extradural space of the anterior cranial fossa, and the sphenoid ridge and base of the anterior clinoid process were displayed at the posterior edge of the anterior skull base (Fig. 2C). The sphenoid ridge and bone lateral to the orbital roof were drilled off 
until the dura mater of the anterior aspect of the temporal lobe and meningoorbital band in the superior orbital fissure were exposed (Fig. 2D). During extradural manipulations, especially for drilling procedures, pulsation of the dura mater was easily controlled with gentle retraction by the endoscope or temporary use of a brain retractor. CSF release by spinal drainage was unnecessary. Orbital unroofing and anterior clinoidectomy were not performed. The dura mater of the anterior aspect of the temporal lobe was incised and opened, exposing the temporal pole in the intradural space (Fig. 2E). Then, a 4-mm, $0^{\circ}$ endoscope was used and a small corticotomy was made to reach the tumor from the anterior trajectory. Thus, the tumor was visualized under an excellent endoscopic view (Fig. 2F). The border of the tumor was well visualized with superb illumination, and total removal was achieved (Fig. 2G). The dura mater was closed with stiches and the slip-knot technique using 6-0 nylon sutures. Duraplasty was reinforced with Gelfoam and fibrin glue, and the supraorbital keyhole was closed. The patient's postoperative course was uneventful, and MRI demonstrated complete removal of the tumor with minimum corticotomy from the anterior trajectory (Fig. 2H). The patient was discharged 1 week after the operation.

\section{Case 2: Sphenoid Ridge Meningioma}

A 78-year-old man presented with epilepsy and left hemiparesis. Gadolinium-enhanced MR images revealed a sphenoid ridge meningioma on the right (Fig. 3A and B). The tumor was widely attached to the dura mater of the anterior and middle cranial fossa. The internal carotid artery (ICA) was not involved, and the middle cerebral artery (MCA) was severely compressed by the tumor. Endoscopic extradural supraorbital surgery was performed (Video 2).

VIDEO 2. Clip showing the pertinent details involved in Case 2. The endoscope is introduced into the extradural space through a supraorbital keyhole. The sphenoid ridge (SR) and bone lateral to the orbital roof are drilled off. The frontotemporal dura mater attached to the tumor is widely exposed. The center of the frontotemporal dura mater is incised, and the tumor is debulked using an ultrasound aspirator. The frontal dura mater is incised along the margin of tumor attachment, and the tumor is detached from the frontal lobe (FL). The ICA is identified medial to the tumor. The MCA adheres strongly to the tumor, and the adherent tumor is left behind. $\mathrm{FD}=$ dura mater of the frontal lobe; $\mathrm{ME}=$ meningioma; $T D=$ dura mater of the temporal lobe; $T L=$ temporal lobe. Copyright Fuminari Komatsu. Published with permission. Click here to view.

A 4-mm, $30^{\circ}$ endoscope was introduced into the extradural space through a supraorbital keyhole. Small feeding arteries from the anterior cranial fossa were coagulated and incised during lifting of the dura mater. The sphenoid ridge and bone lateral to the orbital roof were drilled off (Fig. 3C). Orbital unroofing and anterior clinoidectomy were not performed. Thus, the frontotemporal dura mater attached to the tumor was widely exposed (Fig. 3D). There was a partial defect in the temporal dura mater due to the tumor. The main feeding arteries from the middle meningeal artery were coagulated in the extradural space. Then, the center of the frontotemporal dura mater attached to the tumor was incised to expose the tumor, and it was debulked using an ultrasound aspirator. After debulking, the frontal
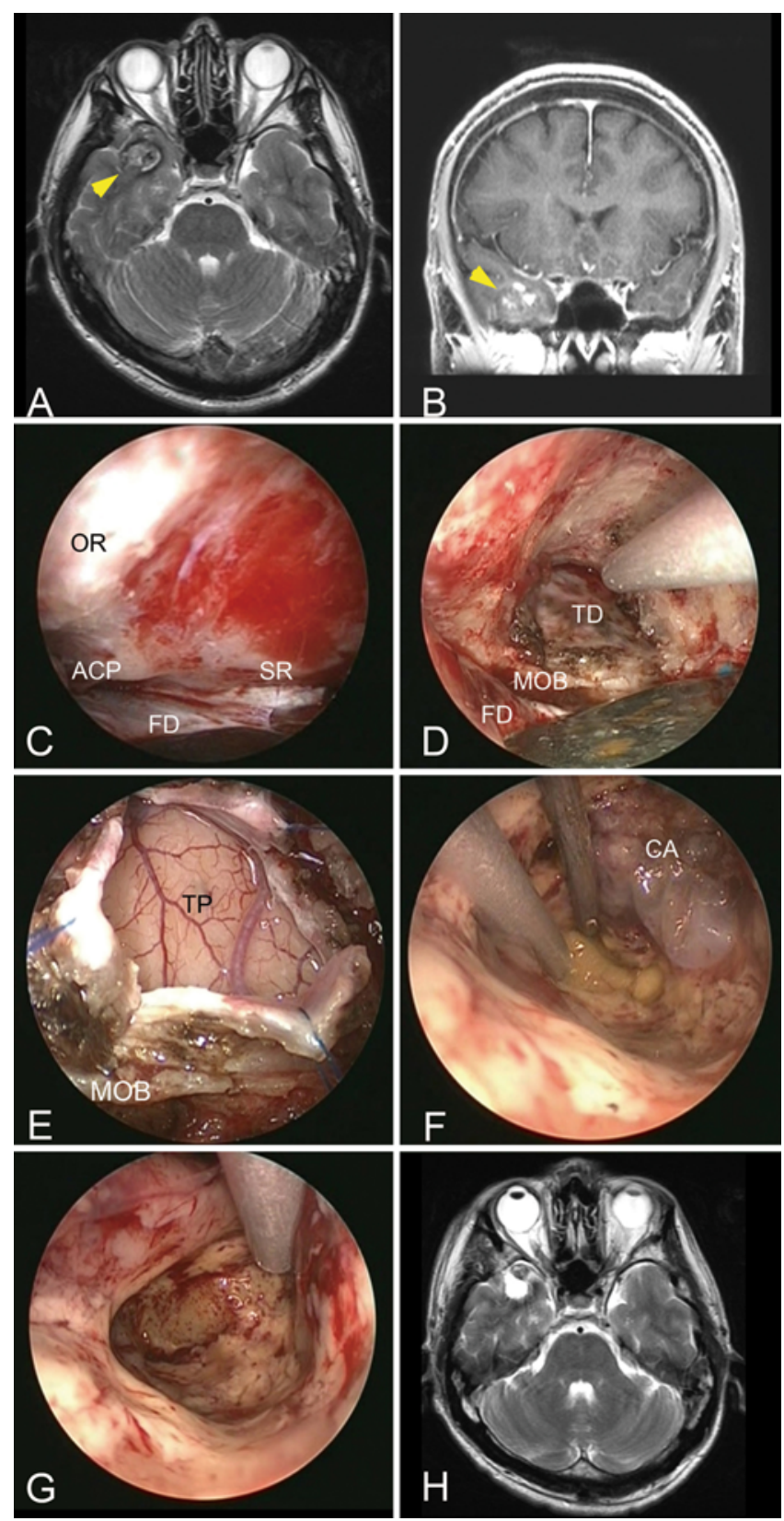

FIG. 2. Case 1. MR images and endoscopic views of a temporal pole cavernous angioma (CA). A and B: Preoperative MR images show a 2-cm cavernous angioma (arrowheads) in the right temporal pole on T2-weighted (A) and Gd-enhanced (B) images. C: The sphenoid ridge $(\mathrm{SR})$ and base of the anterior clinoid process (ACP) are displayed at the posterior edge of the anterior skull base. FD = dura mater of the frontal lobe; $\mathrm{OR}=$ orbital roof. $\mathrm{D}$ : The dura mater of the anterior aspect of the temporal lobe is exposed after drilling. $\mathrm{MOB}=$ meningoorbital band; TD = dura mater of the temporal lobe. E: The dura mater of the anterior aspect of the temporal lobe is opened, exposing the temporal pole (TP) in the intradural space. $\mathbf{F}$ and $\mathbf{G}$ : The cavernous angioma is visualized under an excellent endoscopic view $(F)$, and complete removal is achieved (G). H: Postoperative T2-weighted MR image demonstrates complete removal of the tumor with minimum corticotomy from the anterior trajectory. 

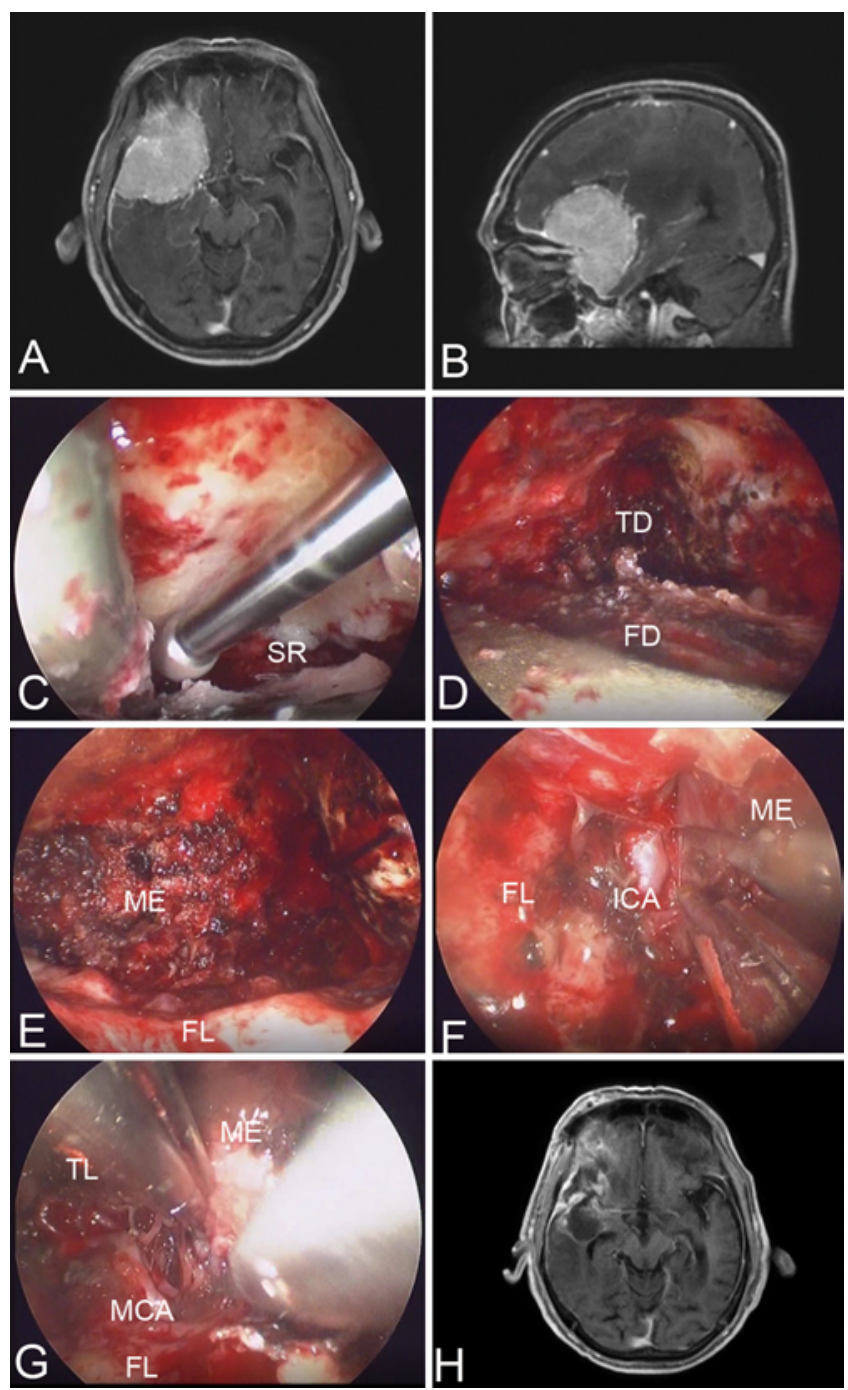

FIG. 3. Case 2. MR images and endoscopic views of a sphenoid ridge meningioma (ME). A and B: Preoperative Gd-enhanced axial (A) and sagittal (B) MR images show a sphenoid ridge meningioma on the right. C: The endoscope is introduced into the extradural space of the anterior cranial fossa, and the sphenoid ridge (SR) and bone lateral to the orbital roof are drilled off. D: The frontotemporal dura mater attached to the tumor is widely exposed. There is a partial defect in the temporal dura mater due to the tumor. FD = dura mater of the frontal lobe; $\mathrm{TD}=$ dura mater of the temporal lobe. $\mathrm{E}$ : The frontal dura mater is incised along the margin of tumor attachment, and the tumor is detached from the frontal lobe (FL). F: The ICA is identified medial to the tumor. G: Branches of the MCA are severely adherent to the tumor, and adherent tumor is left behind. $T L=$ temporal lobe. $\mathrm{H}$ : Postoperative axial Gd-enhanced MR image demonstrates subtotal removal of the tumor.

dura mater was incised along the margin of tumor attachment, and the tumor was detached from the frontal lobe (Fig. 3E). The ICA was identified medial to the tumor, and it was not involved with the tumor (Fig. 3F). In contrast, the $\mathrm{M}_{1}$ segment of the MCA was compressed by the tumor, and the $\mathrm{M}_{2}$ segment arteries were severely adherent to the tumor (Fig. 3G). Therefore, the adherent tumor on the $\mathrm{M}_{2}$ segment was left behind. The tumor compressing the temporal pole and its dural attachment were also removed.
An extensive frontotemporal dural defect was not repaired; instead, duraplasty was performed just beneath the supraorbital keyhole with tenting of the supraorbital dura mater and reinforcement using Gelfoam and fibrin glue. The patient's postoperative course was uneventful without complications, and the left hemiparesis gradually improved. Postoperative MR images showed subtotal removal of the tumor (Fig. 3H). The patient was transferred to a rehabilitation setting 2 weeks after the operation.

\section{Case 3: Cavernous Sinus Pituitary Adenoma}

A 21-year-old woman developed a nonfunctioning pituitary adenoma. Multiple transsphenoidal surgeries had been previously performed due to regrowth of the tumor. Residual tumor was noted in the right cavernous sinus lateral to the ICA after the last endoscopic endonasal surgery (Fig. 4A and B). Pathological examination showed a pituitary adenoma with an MIB-1 index of 5\%. Before radiation therapy, endoscopic extradural supraorbital surgery was performed to reduce tumor volume and promote the effectiveness of radiotherapy (Video 3).

VIDEO 3. Clip showing the pertinent details involved in Case 3. The endoscope is introduced into the extradural space via a supraorbital keyhole. The sphenoid ridge (SR) is identified, and the bone lateral to the orbit is drilled off until the anterior aspect of the temporal dura mater appears. Anterior clinoidectomy is then performed under endoscopic view, and the superior orbital fissure (SOF) is also opened by drilling. The approach to the cavernous sinus is prepared. The frontal and temporal dura mater, meningoorbital band (MOB), orbital roof (OR), optic nerve (II), and clinoidal triangle (CL) are exposed. The tumor is visualized after the clinoidal triangle has been opened. The fibrous tumor is suctioned under endoscopic view. The tumor is then also removed through the anteromedial triangle in the interdural space between the inner and outer layers of the lateral wall of the cavernous sinus. The entire procedure is performed in the extradural space. $\mathrm{ACP}=$ anterior clinoid process; $\mathrm{FD}=$ dura mater of the frontal lobe; $I \mathrm{~L}=$ inner layer of the lateral wall of the cavernous sinus; $\mathrm{OL}=$ outer layer of the lateral wall of the cavernous sinus; $P A=$ pituitary adenoma; $T D=$ dura mater of the temporal lobe. Copyright Fuminari Komatsu. Published with permission. Click here to view.

A 4-mm, $30^{\circ}$ endoscope was introduced into the extradural space via a supraorbital keyhole (Fig. 4C). The bone lateral to the orbital roof was drilled off, and the anterior aspect of the temporal dura mater appeared (Fig. 4D). The anterior clinoid process was then visualized medially, and an anterior clinoidectomy was performed (Fig. 4E). The anterior clinoid process was easily removed because of bone erosion to the optic strut by the tumor. The lateral part of the superior orbital fissure was also opened by drilling. Thus, the temporal and frontal dura mater, meningoorbital band, orbital roof, optic nerve, and clinoidal triangle (Dolenc triangle) were exposed (Fig. 4F). The meningoorbital band was sectioned, the tumor was visualized after the carotid-oculomotor membrane was opened in the clinoidal triangle, and the fibrous tumor was suctioned under endoscopic view (Fig. 4G). During tumor removal, the ICA in the tumor was detected medially by transcranial Doppler ultrasonography, avoiding ICA injury. Furthermore, the interdural space between the inner and outer layers of the lateral wall of the cavernous sinus was exposed with blunt dissection and temporal dura retraction. The tumor was then also removed 

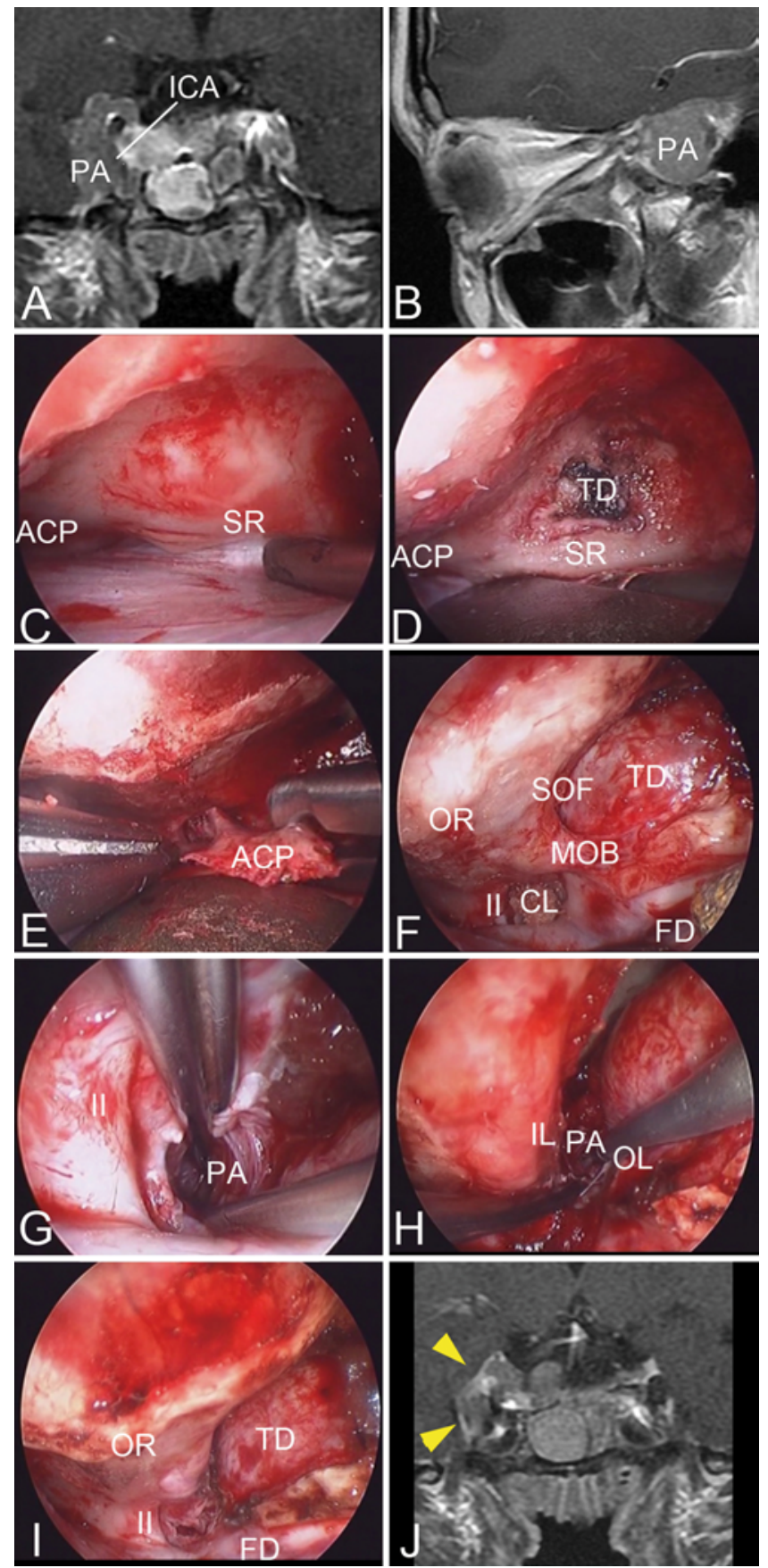

FIG. 4. Case 3. MR images and endoscopic views of the cavernous sinus pituitary adenoma (PA). A and B: Preoperative Gd-enhanced coronal $(A)$ and sagittal $(B)$ MR images show residual tumor after multiple endonasal surgeries in the right cavernous sinus lateral to the ICA. Figure 4A modified from Komatsu F, Shimoda M, Oda S, Imai M, Shigematsu $\mathrm{H}$, Komatsu $\mathrm{M}$, et al: Identification of the internal carotid artery at the superior part of the cavernous sinus during endoscopic endonasal cavernous sinus tumor surgery. Acta Neurochir (Wien) 156:475-479, 2014, with permission from Springer. C: The endoscope visualizes the sphenoid ridge (SR) and base of the anterior clinoid process (ACP) in the extradural space of the anterior cranial fossa. D: The dura mater of the anterior aspect of the temporal lobe is partially exposed after drilling. $\mathrm{TD}=$ dura mater of the temporal lobe. $\mathrm{E}$ : The anterior clinoidectomy is performed under endoscopic visualization. FIG. 4. (continued) $\rightarrow$ through the anteromedial triangle (Mullan triangle; Fig. $4 \mathrm{H})$. Further tumor removal from the other triangles was not performed. The entire procedure was performed in the extradural space, and the intradural space was not exposed; therefore, duraplasty was not needed (Fig. 4I). Postoperative MRI showed partial removal of the tumor (Fig. 4J). Mild oculomotor nerve palsy appeared after the operation, probably due to the nerve compression during tumor removal through the superior cavernous sinus. The patient was discharged 1 week after the operation. The oculomotor nerve palsy had almost resolved 3 months later. In addition to the endoscopic surgery, intensity modulated radiation therapy was performed, and the tumor has been under control for more than 2 years.

\section{Discussion}

This report is the first clinical description of the endoscopic extradural supraorbital approach to the temporal pole. Temporal pole exposure by craniotomy needs wide elevation of the temporal muscle and broad removal of the lateral bone of the middle cranial fossa, resulting in temporal muscle atrophy, disturbed mastication, and poor cosmetic results. Furthermore, the lateral trajectory from the frontotemporal craniotomy does not satisfactorily expose the temporal pole. In contrast, our previous anatomical studies regarding the endoscopic extradural supraorbital approach demonstrated excellent visualization of the middle cranial fossa and temporal pole through the supraorbital keyhole, and the approach eliminated temporal muscle elevation and craniotomy. ${ }^{15,18,19}$ Therefore, mastication discomfort was avoided even with temporal pole surgery. The trajectory from the anterior direction was optimal to visualize the temporal pole, and it minimized the corticotomy on the temporal pole. A dural incision in the deep surgical field reduced brain exposure, and the opened dura mater could be simply closed using the slip-knot technique. ${ }^{12}$ This technique was originally reported for duraplasty of the sella turcica during endoscopic pituitary surgery; the knot made in a special manner outside the surgical field is slipped onto the surgical field without a knot pusher. This simple and easy technique was also useful for duraplasty in endoscopic keyhole surgery.

In addition, using the extradural space brings some benefits for endoscopic keyhole surgery. Although instrumentation under endoscopy carries potential risks of damage to neurovascular structures behind the tip of the endoscope, insertion and withdrawal of surgical instruments is basically safe, because the extradural space, where there

FIG. 4. F: After drilling, the extradural space is widely exposed through the supraorbital keyhole. The temporal and frontal dura mater, meningoorbital band (MOB), orbital roof (OR), optic nerve (II), and clinoidal triangle (CL; Dolenc triangle) are demonstrated. $\mathrm{FD}=$ dura mater of the frontal lobe; SOF = superior orbital fissure. G: The tumor is removed after the clinoidal triangle has been opened lateral to the optic nerve. $\mathrm{H}$ : The tumor is also removed through the anteromedial triangle (Mullan triangle) in the interdural space between the inner (IL) and outer layers $(\mathrm{OL})$ of the lateral wall of the cavernous sinus. I: Tumor removal is accomplished without opening the intradural space. J: Postoperative Gd-enhanced MR image showing partial removal of the tumor (arrowheads). 
are no vital structures, is used. Similarly, drilling under endoscopy in the intradural space is associated with the risk of damage to neurovascular structures, but using the extradural space for drilling would result in a substantial reduction of such risks and allow the introduction of the skull base technique, even under endoscopy.

Compared with different endoscopic approaches to the temporal pole, the endoscopic extradural supraorbital approach has the ability to expand the accessible area ${ }^{4,14}$ The applicable area of exposure is similar to that in the conventional extradural frontotemporal approach by craniotomy. Depending on the target pathology, bone removal in the extradural space would be modified, and the optimal corridor could be prepared. Unroofing of the orbit and optic canal allows an approach around the optic apparatus, and furthermore, an anterior clinoidectomy can expose the superior and lateral walls of the cavernous sinus. In addition to the dural incision around the target pathology, a dural incision beneath the supraorbital keyhole as in the conventional endoscopic supraorbital approach would allow wide exposure of the anterior skull base territory. Sphenoid ridge and paraclinoid meningiomas and pituitary adenomas protruding into the middle cranial fossa would be included as preferred candidates in the expanded corridor.

Excellent visibility with superb illumination is the great advantage of endoscopic surgery compared with microscopic surgery, but difficulty performing microsurgical manipulation such as tumor separation from the cranial nerves and perforators may become a surgical limitation of endoscopic surgery. This technical limitation should be considered when determining whether endoscopic keyhole surgery is indicated. It is expected that development of novel instruments and technical advancements will overcome this limitation of endoscopic keyhole surgery.

Potential major complications include venous bleeding from the sphenoparietal sinus. Indocyanine green angiography under endoscopy before dural incision of the anterior aspect of the temporal lobe dura may be useful to avoid damage to the sphenoparietal sinus by depiction of the venous system, although there was no opportunity to introduce this method in the present study. ${ }^{11}$

Finally, the endoscopic extradural supraorbital approach was safe and effective in clinical cases. This technique could be considered as an alternative for temporal pole surgery. Sufficient endoscopic experience and comprehension of the related endoscopic skull base anatomy are mandatory for this technique.

\section{Conclusions}

The endoscopic extradural supraorbital approach to the temporal pole presented in this paper was technically feasible. The anterior trajectory to the temporal pole using extradural space under endoscopy is believed to enhance visibility and safety. Further surgical experience and development of novel instruments would promote the establishment of this approach as a minimally invasive surgical option.

\section{Acknowledgments}

We greatly appreciate the assistance of Professor Manfred
Tschabitscher of Brescia University, Italy, for teaching the endoscopic anatomy related to this surgical technique, and Dr. Mika Komatsu of Ohta Neurosurgical Clinic, Japan, for cooperation with previous anatomical studies and cordial advice regarding this study.

\section{References}

1. Berhouma M, Jacquesson T, Jouanneau E: The fully endoscopic supraorbital trans-eyebrow keyhole approach to the anterior and middle skull base. Acta Neurochir (Wien) 153:1949-1954, 2011

2. Cappabianca P, Cavallo LM, Esposito F, De Divitiis O, Messina A, De Divitiis E: Extended endoscopic endonasal approach to the midline skull base: the evolving role of transsphenoidal surgery. Adv Tech Stand Neurosurg 33:151-199, 2008

3. Cavallo LM, Messina A, Cappabianca P, Esposito F, de Divitiis E, Gardner P, et al: Endoscopic endonasal surgery of the midline skull base: anatomical study and clinical considerations. Neurosurg Focus 19(1):E2, 2005

4. Chen HI, Bohman LE, Emery L, Martinez-Lage M, Richardson AG, Davis KA, et al: Lateral transorbital endoscopic access to the hippocampus, amygdala, and entorhinal cortex: initial clinical experience. ORL J Otorhinolaryngol Relat Spec 77:321-332, 2015

5. Ditzel Filho LF, McLaughlin N, Bresson D, Solari D, Kassam AB, Kelly DF: Supraorbital eyebrow craniotomy for removal of intraaxial frontal brain tumors: a technical note. World Neurosurg 81:348-356, 2014

6. Dolenc V: Direct microsurgical repair of intracavernous vascular lesions. J Neurosurg 58:824-831, 1983

7. Dolenc VV: Transcranial epidural approach to pituitary tumors extending beyond the sella. Neurosurgery 41:542-552, 1997

8. Frank G, Pasquini E: Endoscopic endonasal approaches to the cavernous sinus: surgical approaches. Neurosurgery 50:675, 2002

9. Hakuba A, Tanaka K, Suzuki T, Nishimura S: A combined orbitozygomatic infratemporal epidural and subdural approach for lesions involving the entire cavernous sinus. J Neurosurg 71:699-704, 1989

10. Harris FS, Rhoton AL: Anatomy of the cavernous sinus. A microsurgical study. J Neurosurg 45:169-180, 1976

11. Hide T, Yano S, Shinojima N, Kuratsu J: Usefulness of the indocyanine green fluorescence endoscope in endonasal transsphenoidal surgery. J Neurosurg 122:1185-1192, 2015

12. Ishii Y, Tahara S, Oyama K, Kitamura T, Teramoto A: Easy slip-knot: a new simple tying technique for deep sutures. Acta Neurochir (Wien) 153:1543-1545, 2011

13. Kabil MS, Shahinian HK: Application of the supraorbital endoscopic approach to tumors of the anterior cranial base. J Craniofac Surg 16:1070-1075, 2005

14. Kabil MS, Shahinian HK: The endoscopic supraorbital approach to tumors of the middle cranial base. Surg Neurol 66:396-401, 2006

15. Komatsu F, Komatsu M, Di Ieva A, Tschabitscher M: Endoscopic approaches to the trigeminal nerve and clinical consideration for trigeminal schwannomas: a cadaveric study. J Neurosurg 117:690-696, 2012

16. Komatsu F, Komatsu M, Di Ieva A, Tschabitscher M: Endoscopic extradural subtemporal approach to lateral and central skull base: a cadaveric study. World Neurosurg 80:591-597, 2013

17. Komatsu F, Komatsu M, Di Ieva A, Tschabitscher M: Endoscopic far-lateral approach to the posterolateral craniovertebral junction: an anatomical study. Neurosurg Rev 36:239-247, 2013

18. Komatsu F, Komatsu M, Inoue T, Tschabitscher M: Endo- 
scopic extradural anterior clinoidectomy via supraorbital keyhole: a cadaveric study. Neurosurgery 68 (2 Suppl Operative):334-338, 2011

19. Komatsu F, Komatsu M, Inoue T, Tschabitscher M: Endoscopic supraorbital extradural approach to the cavernous sinus: a cadaver study. J Neurosurg 114:1331-1337, 2011

20. Komatsu F, Shimoda M, Oda S, Imai M, Shigematsu H, Komatsu M, et al: Identification of the internal carotid artery at the superior part of the cavernous sinus during endoscopic endonasal cavernous sinus tumor surgery. Acta Neurochir (Wien) 156:475-479, 2014

21. Wilson DA, Duong H, Teo C, Kelly DF: The supraorbital endoscopic approach for tumors. World Neurosurg 82:e243e256, 2014

\section{Disclosures}

The authors report no conflict of interest concerning the materials or methods used in this study or the findings specified in this paper.

\section{Author Contributions}

Conception and design: Komatsu. Acquisition of data: Komatsu, Imai, Shigematsu, Oda, Shimoda. Analysis and interpretation of data: Komatsu. Drafting the article: Komatsu. Critically revising the article: Komatsu. Reviewed submitted version of manuscript: Komatsu, Matsumae. Approved the final version of the manuscript on behalf of all authors: Komatsu. Administrative/technical/ material support: Aoki. Study supervision: Matsumae.

\section{Supplemental Information}

Videos

Video 1. https://vimeo.com/215024056.

Video 2. https://vimeo.com/215024259.

Video 3. https://vimeo.com/215024386.

\section{Correspondence}

Fuminari Komatsu, Department of Neurosurgery, Tokai University Hachioji Hospital, 1838 Ishikawa-machi, Hachioji, Tokyo 192-0032, Japan. email: fuminarikomatsu@gmail.com. 